\title{
Brachial-Ankle Pulse Wave Velocity: Background, Method, and Clinical Evidence
}

\author{
Masanori Munakata \\ Research Center for Lifestyle-Related Disease and Division of Hypertension, \\ Japan Health, Labor, and Welfare Organization, Tohoku Rosai Hospital, Sendai, Japan
}

\section{Key Words}

Ageing · Arterial stiffness · Cardiovascular disease · Hypertension · Pulse wave velocity

\begin{abstract}
Background: The populations of many developed countries are becoming progressively older. In aged societies, assessment of total vascular risk is critically important, because old age is usually associated with multiple risks. In this regard, pulse wave velocity (PWV) could be a global cardiovascular marker, since it increases with advancing age, high blood pressure, hyperglycaemia, and other traditional risks, summating cardiovascular risks. Carotid-femoral PWV has been widely applied in Western countries and has been used as a gold-standard PWV measure. However, this measure has never been implemented by general practitioners in Japan, possibly because of methodological difficulties. The life expectancy of Japanese people is now the highest in the world, and the establishment of an adequate total vascular risk measure is an urgent need. Against this background, brachial-ankle PWV was developed at the beginning of this century. Summary: Measurement of this parameter is easy, and its reproducibility is good. Moreover, the generality of the methodology is guaranteed. Brachialankle PWV has been reported to consistently increase with most traditional cardiovascular risk factors except dyslipidaemia. A meta-analysis of cohort studies including various levels of risk has shown that a $1 \mathrm{~m} / \mathrm{s}$ increase in brachial-ankle PWV is associated with a $12 \%$ increase in the risk of cardiovascular events. Moreover, simultaneous evaluation of the ankle-brachial index could allow further risk stratification of high-risk individuals, who are common in aged societies. This unique feature is indispensable for the management of aged populations, who usually are exposed to multiple risks and have polyvascular diseases. This evidence, however, is chiefly derived from East Asian countries. The collection of data from Caucasian populations, therefore, remains a task for the future. Key Message: Brachial-ankle PWV has the potential to become a measure of arterial stiffness worldwide.


Munakata et al.: Brachial-Ankle Pulse Wave Velocity: Background, Method, and Clinical Evidence

\section{Background}

Ageing of society is a common issue in many developed countries. The life expectancies of Japanese people have extended by about 25 years during the previous 5 decades [1]. This is largely attributable to the introduction of a universal health care system in 1961 and the establishment of free access to medical facilities. In fact, systolic blood pressure values have been reduced by about 10-20 $\mathrm{mm} \mathrm{Hg}$ throughout all generations during the past 50 years [2], resulting in a marked reduction in the incidence of stroke, a leading cause of death among Japanese until 1980. However, the prolongation of the life expectancy of Japanese people has not been associated with a consistently healthy life but with one with some periods of disability [3]. Many factors cause disability among aged Japanese individuals, but cerebrovascular diseases have been suggested to play the most important role [4]. Thus, healthier vascular ageing is of great concern to Japanese society.

Regarding arterial health, William Osler stated: 'Man is as old as his arteries'. More specifically, arterial stiffness has been considered as a measure of biological ageing. Arterial stiffness refers to the rigidity of the arterial wall. The arterial wall progressively stiffens because of ageing, which is associated with various kinds of biochemical and histologic changes in the arterial wall [5]. Moreover, increased intraluminal pressure, or hypertension, could increase arterial wall stress and functionally stiffens the arterial wall. Thus, arterial stiffness reflects the summation of both organic and functional stiffness of the arterial wall. Because high blood pressure is the most important risk factor for cardiovascular diseases in the Japanese population [6], an arterial measure which reflects the influence of blood pressure would be an adequate marker for total vascular risk in Japanese people. In this regard, arterial stiffness might be a good candidate.

The ejection of blood from the heart produces an arterial pulsation termed 'pulse wave', and the speed at which it propagates to the periphery is called 'pulse wave velocity' (PWV). The PWV is known to be proportional to the rigidity of the arterial wall through which it propagates and inversely proportional to the vessel diameter. In Japan, a unique technique for measuring aortic PWV was developed around 1970 [7] and had been suggested as a marker of atherosclerosis [8]. At the same time, analysis of finger photoplethysmographic waveforms was first introduced by Ozawa (in Japanese), and its clinical usefulness as a measure of vascular ageing was later established by Takazawa et al. [9]. In Western countries, carotid-femoral PWV (cfPWV) has been a popular method for evaluating large-artery stiffness [10], which was more importantly considered as a measure of buffering function moderating cardiac load or arterial oscillation. Several automatic devices have been introduced for the measurement of cfPWV $[11,12]$, and a vast amount of clinical data has been accumulated. In Japan, the use of these devices, however, was still limited in the research field, possibly because of their limited availability to general practitioners. Brachial-ankle PWV (baPWV) was developed in this historical situation in about the year 2000.

\section{Theoretical Concept of baPWV and Its Validation}

PWV is calculated by dividing travelled distance by travel time [5]. The pulse wave is preferentially measured between two points on the same artery (fig. 1a), but this can only be applied to peripheral PWV such as brachial-radial or femoral-tibial PWV. The stiffness of the large artery is considered more important than that of the peripheral artery. In this case, it is not easy to apply this method, because the proximal aortic wave is difficult to measure from the body surface. In this case, the arterial wave on the branching artery can be used instead (fig. 1b). In baPWV measurements, the brachial arterial wave is used to substitute for the 
Fig. 1. Theoretical concepts for the measurement of PWV. D = Distance; $\mathrm{T}=$ time.
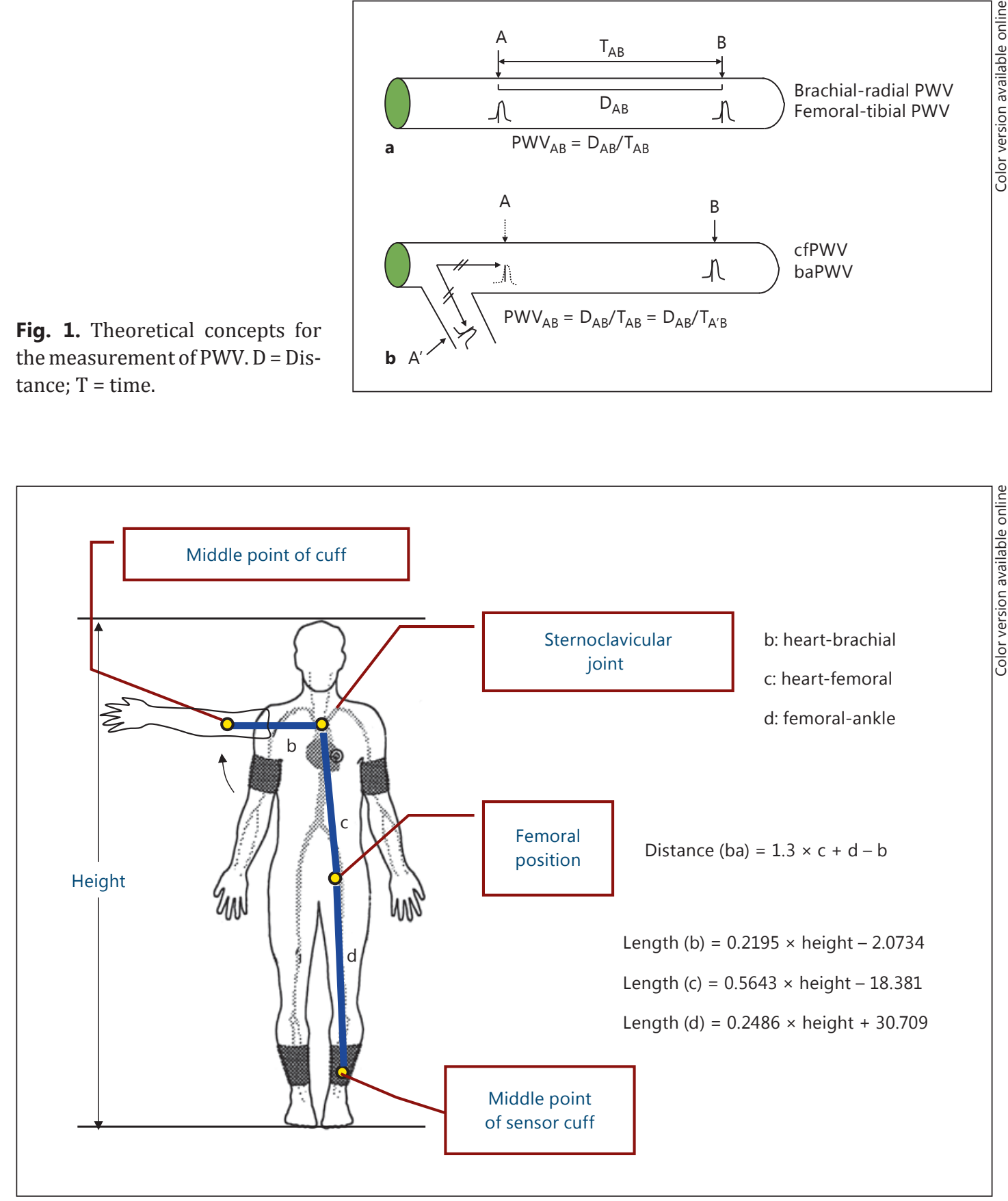

Fig. 2. Path length formula for baPWV.

proximal aortic wave. The path length formula is critically important when we measure PWV. Figure 2 shows how to calculate the brachial-ankle distance, with b, c, and d indicating heartbrachial, heart-femoral, and femoral-ankle lengths. All these lengths are expressed as linear equations of height as shown in figure 2. Brachial-ankle distance is expressed as $1.3 \times \mathrm{c}+$ $d-b$. Thus, it is also expressed as a linear equation of height. Recently, this height-based path length has been validated by comparing the path length determined by using the magnetic 
Munakata et al.: Brachial-Ankle Pulse Wave Velocity: Background, Method, and Clinical Evidence

resonance imaging (MRI) method [13]. The results showed that the brachial-ankle path length overestimated the MRI-based path length by about $11 \%$ because of the underestimation of the heart-brachial distance, or b. This is one of the reasons why baPWV shows a greater absolute value than cfPWV or femoral-ankle PWV [14]. However, the correlation between height-based baPWV and MRI-based baPWV was high $\left(r^{2}=0.96\right)$, suggesting that the MRIbased baPWV can be easily converted from the height-based baPWV. The intra- and interobserver variabilities of baPWV are reportedly $3.8-10.0 \%$ and $3.6-8.4 \%$, respectively, representing a reproducibility that is not problematic in clinical use [5].

\section{Disease Specificity of baPWV and Treatment Effects}

We have recently summarised disease-specific changes in baPWV or changes in various pathophysiological conditions [5]. Briefly, baPWV increases in patients with hypertension, diabetes, metabolic syndrome, chronic kidney disease, and sleep apnoea syndrome, as well as in the conditions of ageing, tachycardia, and post-menopause. In hypertension and diabetes, higher baPWV is associated with more advanced organ damage. The relationship between baPWV and lipids is not in accord. baPWV also increases in end-stage renal disease, and higher baPWV is associated with lower cardiac function, left ventricular hypertrophy, and severity of carotid atherosclerosis. However, because the prevalence of peripheral arterial disease (PAD) in end-stage renal disease has been reported to range from 20 to $30 \%$, baPWV is of limited usefulness in a considerable proportion of cases. Regarding treatment effects, antihypertensive agents, statins, oral diabetic drugs, weight loss, smoking cessation, and continuous positive airway pressure have been reported to lower baPWV.

Only a few studies have examined whether baPWV could be a marker of surrogate end points. One study reported that in 161 patients with coronary artery disease, the risk of coronary artery disease onset and mortality rates were about 4 times higher in the group without than in the group with a decrease in baPWV after therapeutic intervention [15]. In hypertensive patients, changes in baPWV and urinary albumin excretion after 6 months of antihypertensive therapy were correlated, and the group with reduced baPWV had a greater reduction in urinary albumin excretion than the group without reduced baPWV [16]. In a randomised controlled trial that compared the degree of intimal formation after stenting and baPWV between a telmisartan and a valsartan treatment group of patients with coronary disease, the telmisartan group showed less neointima formation and significantly lower baPWV than the valsartan group [17]. It has been well established that coronary artery calcium (CAC) is significantly correlated with the risk of coronary heart disease and poor prognosis. Lee et al. [18] examined the relationship between baPWV and future progression of CAC in 1,124 subjects who voluntarily underwent comprehensive health screenings. During the mean follow-up period of 2.7 years, an increased CAC score was found in 318 subjects. When the subjects were grouped as quartiles according to baPWV level, the 3rd- and 4th-quartile groups showed a significantly higher odds ratio for progression of the CAC score (2.04, 95\% CI 1.33-3.15, and 2.14, 95\% CI 1.34-3.41, respectively) than the lowest-quartile group ( $\mathrm{p}$ for trend $<0.001$ ).

\section{Prognostic Significance of baPWV}

Table 1 summarises the cohort studies performed to date. The results were summarised until No. 14 in a recent review [5]. This paper describes further evidence added by study No. 15 and thereafter. In untreated patients with essential hypertension, the cut-off value of 
Munakata et al.: Brachial-Ankle Pulse Wave Velocity: Background, Method, and Clinical Evidence

Table 1. Studies on the prognostic significance of baPWV in Japan

\begin{tabular}{|c|c|c|c|c|c|c|}
\hline $\begin{array}{l}\text { Report } \\
\text { No. }\end{array}$ & Authors [Ref.], year & Cohort & $\begin{array}{l}\text { Mean age, } \\
\text { years }\end{array}$ & Follow-up & Outcomes & $\begin{array}{l}\text { Prognostic value } \\
\text { of baPWV }\end{array}$ \\
\hline 1 & Kitahara et al. [31], 2005 & 785 haemodialysis patients & 60 & 34 months & $\begin{array}{l}\text { Total death } 131 \\
\text { CV death } 85\end{array}$ & Significant \\
\hline 2 & Tomiyama et al. [32], 2005 & $\begin{array}{l}215 \text { acute coronary syndrome } \\
\text { patients }\end{array}$ & No data & 26 months & CV events 18 & Significant \\
\hline 3 & Morimoto et al. [33], 2009 & 199 haemodialysis patients & 61 & 43.2 months & $\begin{array}{l}\text { Total death } 24 \\
\text { CV death } 10\end{array}$ & Significant \\
\hline 4 & Meguro et al. [34], 2009 & $72 \mathrm{CHF}$ patients & 68 & 14 months & $\begin{array}{l}\text { Readmission due to CHF } 17 \\
\text { Cardiac death } 9\end{array}$ & Significant \\
\hline 5 & Miyano et al. [35], 2010 & $\begin{array}{l}530 \text { elderly subjects from the } \\
\text { general population }\end{array}$ & 76 & 3 years & $\begin{array}{l}\text { Total death } 30 \\
\text { CV death } 10\end{array}$ & Significant \\
\hline 6 & Nakamura et al. [36], 2010 & 191 diabetic patients with CAD & No data & 25.4 months & Composite CV events 59 & Significant \\
\hline 7 & Turin et al. [37], 2010 & $\begin{array}{l}2,480 \text { subjects from the general } \\
\text { population }\end{array}$ & $\begin{array}{l}\text { Men } 61 \\
\text { Women } 57\end{array}$ & 6.5 years & Total death 59 & Significant \\
\hline 8 & Kato et al. [38], 2010 & 194 haemodialysis patients & 64 & 39 months & $\begin{array}{l}\text { Total death } 39 \\
\text { CV events } 39\end{array}$ & Not significant \\
\hline 9 & Tanaka et al. [39], 2011 & 445 haemodialysis patients & 63 & 43 months & $\begin{array}{l}\text { CV events } 206 \\
\text { CV death } 36\end{array}$ & Not significant \\
\hline 10 & Yoshida et al. [40], 2012 & 783 diabetic patients & No data & 5.4 years & CV events 85 & Not significant \\
\hline 11 & Munakata et al. [19], 2012 & 662 hypertensive patients & 60 & 3 years & CV events 24 & Significant \\
\hline 12 & Inoue et al. [41], 2012 & 197 haemodialysis patients & 66 & 69 months & CV events 89 & Significant \\
\hline 13 & Ninomiya et al. [23], 2013 & $\begin{array}{l}2,916 \text { subjects from the general } \\
\text { population }\end{array}$ & 60 & 7.1 years & CV events 126 & Significant \\
\hline 14 & Takashima et al. [24], 2014 & $\begin{array}{l}4,164 \text { subjects from the general } \\
\text { population }\end{array}$ & 58.9 & 6.5 years & CV events 40 & Significant \\
\hline 15 & Kawai et al. [20], 2013 & 440 hypertensive patients & 61 & 6.3 years & CV events 62 & Significant \\
\hline 16 & Ishisone et al. [25], 2013 & $\begin{array}{l}973 \text { subjects from the general } \\
\text { population }\end{array}$ & 59 & 7.8 years & CV events 37 & Significant \\
\hline 17 & Maeda et al. [21], 2014 & 3,628 diabetic patients & 61 & 3.2 years & $\begin{array}{l}\text { Total death } 207 \\
\text { CV events } 298\end{array}$ & Significant \\
\hline 18 & Katakami et al. [22], 2014 & 1,040 diabetic patients & 59 & 7.5 years & CV events 113 & Significant \\
\hline 19 & Sugamata et al. [30], 2014 & 923 CAD patients & 65 & 64 months & Coronary events 116 & Significant \\
\hline
\end{tabular}

baPWV at which the cardiovascular event risk begins to increase has been shown to be at $1,750 \mathrm{~cm} / \mathrm{s}$ according to the results of the Japanese Trial on the Prognostic Implication of Pulse Wave Velocity [19]. However, whether this cut-off value could be applied to treated patients with essential hypertension was unclear. In the Non-Invasive Atherosclerosis Evaluation in Hypertension study, 440 patients treated for essential hypertension were followed up for 6.3 years, and the relationship between baPWV and risk of cardiovascular events was examined [20]. During the follow-up period, 35 stroke, 30 cardiovascular disease, and 62 stroke-plus-cardiovascular-disease cases were found. A receiver operating characteristic curve analysis showed that the best cut-off value to maximise sensitivity and 1 - specificity was $1,736 \mathrm{~cm} / \mathrm{s}$ for both stroke and cardiovascular events. The multivariate adjusted hazard ratios for stroke, cardiovascular disease, and stroke plus cardiovascular disease in a group with a baPWV of $\geq 1,750 \mathrm{~cm} / \mathrm{s}$ were 1.828 (95\% CI 0.879-3.870), 1.786 (95\% CI 0.796-4.101), and 2.048 (95\% CI 1.176-3.616), respectively, in comparison with the group with a baPWV of $<1,750 \mathrm{~cm} / \mathrm{s}$. This confirmed that a baPWV of $1,800 \mathrm{~cm} / \mathrm{s}$ could also be a threshold for high risk in patients treated for essential hypertension.

In my recent review, the prognostic significance of baPWV in diabetic patients was controversial [5], as suggested by reports No. 6 and 10 in table 1. However, study No. 10 was retrospective and did not exclude patients with PAD. baPWV has been shown to markedly underestimate cardiovascular risk in patients with PAD, in whom the prognostic value of baPWV is eliminated [5]. Study No. 1 in table 1 showed that in patients with end-stage renal disease, baPWV was a significant predictor of cardiovascular events if patients with an anklebrachial index (ABI) of $<0.9$ were excluded beforehand, while the significance disappeared if 
Table 2. Prognostic studies on baPWV outside Japan

\begin{tabular}{|c|c|c|c|c|c|c|c|}
\hline $\begin{array}{l}\text { Report } \\
\text { No. }\end{array}$ & Authors [Ref.], year & Country & Cohort & $\begin{array}{l}\text { Mean } \\
\text { age, } \\
\text { years }\end{array}$ & Follow-up & Outcomes & $\begin{array}{l}\text { Prognostic } \\
\text { value of } \\
\text { baPWV }\end{array}$ \\
\hline 1 & Chang et al. [42], 2014 & Taiwan & 452 diabetic patients & 67 & 5.8 years & $\begin{array}{l}\text { Total death } 17 \\
\text { Composite CV events } 64\end{array}$ & Significant \\
\hline 2 & Yoon et al. [43], 2014 & Korea & 241 CKD patients & 53 & 367 days & CV events 12 & Significant \\
\hline 3 & Kim et al. [27], 2014 & Korea & 1,765 acute ischaemic stroke patients & 65 & 3.3 years & $\begin{array}{l}\text { Total death } 228 \\
\text { Vascular death } 143\end{array}$ & Significant \\
\hline 4 & Sheng et al. [28], 2014 & China & 3,876 subjects from the general population & 68 & 5.9 years & Total death 316 & Significant \\
\hline
\end{tabular}

such pre-treatment was absent. In the Kyusyu Prevention Study of Atherosclerosis [21], 3,628 diabetic patients with an ABI of $\geq 0.9$ were prospectively followed up. During the mean followup period of 3.2 years, 298 cerebrovascular and cardiovascular events and 207 total deaths occurred. The risks of cerebrovascular events, cardiovascular events, and total mortality were all increased with an increase in baPWV. The multivariate adjusted odds ratio for total mortality in the group with a baPWV of $\geq 24 \mathrm{~m} / \mathrm{s}$ was 1.84 (95\% CI 1.13-2.88) in comparison with the group with a baPWV of $<24 \mathrm{~m} / \mathrm{s}$. Moreover, the multivariate adjusted odds ratios for cerebrovascular and cardiovascular events in the group with a baPWV of $\geq 14 \mathrm{~m} / \mathrm{s}$ were 1.56 (95\% CI 1.03-2.45) and 1.16 (95\% CI 0.82-1.68), respectively. In the Order-Made Multiple Risk Factor Intervention Trial, 1,040 type 2 diabetic patients without PAD were followed up for 7.5 years [22]. The unique point of this study was that the intima media thickness (IMT) of the carotid artery was added as a covariate. During the mean follow-up period of 7.5 years, 113 new-onset cardiovascular events occurred. The multivariate adjusted hazard ratio for cardiovascular events in the group with a baPWV of $\geq 1,550 \mathrm{~cm} / \mathrm{s}$ was 1.35 (95\% CI 1.111.64), and the inclusion of maximum IMT minimally affected the hazard ratio $1.33 ; 95 \% \mathrm{CI}$ 1.09-1.62). These data clearly demonstrated that baPWV was an independent predictor of cardiovascular events in diabetic patients when patients with PAD were excluded, and that the predictive value was never reduced even after inclusion of IMT as a covariate.

A series of cohort studies conducted in the general population have consistently shown the close relationship between baPWV and cardiovascular events. In the Hisayama study, the correlation between baPWV and cardiovascular disease risk was continuous and a $20 \%$ increase in baPWV was associated with a 1.3-fold increase in the risk of cardiovascular events [23]. The latest data from the Takashima study indicated that at $\geq 1,800 \mathrm{~cm} / \mathrm{s}$, the risk of cardiovascular events was 2.7 -fold higher than at $<1,800 \mathrm{~cm} / \mathrm{s}$ [24]. Ishisone et al. [25] recently compared the prognostic value of baPWV, central blood pressure, and brachial pulse pressure for cardiovascular morbidity and mortality in 973 subjects from the general population aged 40-79 years (mean 59 years). During the mean follow-up period of 7.8 years, 37 cardiovascular events and deaths occurred. The relationship between the cardiovascular outcomes and quartiles of each measure was examined. baPWV showed a significant relationship with cardiovascular outcome, while the other two measures did not. They concluded that baPWV may be a better predictor of cardiovascular events than central blood pressure or pulse pressure in the general Japanese population. These results are similar to those obtained in the Framingham Cohort Study that showed that cfPWV was a significant predictor of cardiovascular events, whereas neither central blood pressure nor augmentation index was [26]. These data suggest that PWV could be the best predictor of cardiovascular events among several arterial stiffness measures in the general population. 
Munakata et al.: Brachial-Ankle Pulse Wave Velocity: Background, Method, and Clinical Evidence

Results of several recent cohort studies from East Asian countries have been reported as shown in table 2. Kim et al. [27] examined the relationship between baPWV and vascular and non-vascular mortality in patients with acute ischaemic stroke. More than 1,700 patients with ischaemic stroke were followed up for up to 7 years. Both vascular and non-vascular mortality rates increased with an elevation of baPWV. The highest tertile of baPWV was associated with a 2.4 times higher risk of vascular mortality as compared with the reference group. A $10 \mathrm{~m} / \mathrm{s}$ increase in baPWV was associated with a $62 \%$ increase in the risk of vascular mortality. Sheng et al. [28] examined the relationship between baPWV and all-cause mortality in an elderly Chinese population. The adjusted hazard ratio for all-cause mortality in the top decile group of baPWV was 1.56 (95\% CI 1.16-2.08) as compared with the whole study population. In this study, the adjusted hazard ratio for non-cardiovascular mortality was significant (HR 1.60; 95\% CI 1.18-2.75), while that for cardiovascular mortality did not reach a statistically significant level (HR 1.46; 95\% CI 0.90-2.05).

\section{Use of baPWV in Combination with ABI}

In general, PWV measurement becomes unreliable if the circulation is disturbed on the way of pulse propagation [14]. Thus, confirming the normal circulation of the lower limb artery from the iliac to the tibial region is critically important in the measurement of baPWV. In this regard, both sides of the ABI measurements are mandatory before considering the use of baPWV. The recommended diagnostic and/or therapeutic procedures are as follows. First, the presence/absence of PAD should be verified based on the ABI. PAD is suspected if the ABI on either the left or the right side is $\leq 0.9$; therefore, patients with this condition are considered a high-risk group and need to be more closely examined. If necessary, drug therapy is started/ intensified. In such instances, stenosis would be suspected in the lower limb arteries; therefore, it is difficult to attach significance to the baPWV value, and it is not used as a clinical indicator.

$\mathrm{An} \mathrm{ABI}$ of $>0.9$ on both the left and the right side indicates the absence of severe arteriosclerosis obliterans; therefore, baPWV has prognostic significance. Such patients are at high risk of cardiovascular events if the baPWV on either side is $\geq 1,800 \mathrm{~cm} / \mathrm{s}$ and therefore require thorough management of cardiovascular risks, which could increase the baPWV as noted earlier. If both baPWV values are $<1,800 \mathrm{~cm} / \mathrm{s}$ but either baPWV is $\geq 1,400 \mathrm{~cm} / \mathrm{s}$, the risk of hypertension onset or decline in renal function is high. Therefore, lifestyle modifications are recommended [5]. These are valid clinical applications of baPWV as considered from the evidence accumulated thus far.

\section{Conclusions and Future Issues}

baPWV has been well confirmed to increase in conditions with traditional cardiovascular risk factors such as ageing, hypertension, diabetes, and chronic kidney disease. Thus, baPWV could summate total vascular risks. Moreover, accumulated evidence from East Asian countries has shown that baPWV has a good prognostic significance independent of traditional risk factors in many cohorts with various risk levels. Moreover, simultaneous measurement of the ABI could further stratify high-risk individuals. In other words, the combined use of the $\mathrm{ABI}$ and baPWV could serially stratify cardiovascular risk in populations with various degrees of vascular damage. This unique feature is indispensable in the management of aged populations, who are usually exposed to multiple risks and have polyvascular diseases. Measurement of this measure is easy, with good reproducibility. Moreover, the generality of the method- 
ology is guaranteed. Thus, baPWV has the potential to become a global measure of arterial stiffness. As yet, baPWV has never been fully accepted worldwide due to perceived theoretical and methodological issues [29]. To bridge the gap and further confirm the clinical usefulness of baPWV, the following two issues should be adequately addressed. First, the data on Caucasian populations are extremely limited; thus, more data are needed on these populations. Second, whether baPWV-guided therapy could really improve prognosis for high-risk individuals remains unclear; to clarify this issue, a randomised controlled trial with baPWV as the decision marker for treatment should be conducted.

\section{Acknowledgement}

This study was supported in part by grants from the Miyagi Prefectural Kidney Association.

\section{Disclosure Statement}

The author has no conflicts of interest to disclose.

\section{References}

1 OECD Data Japan. 2015. https://data.oecd.org/japan.htm.

2 Miura K, Nagai M, Ohkubo T: Epidemiology of hypertension in Japan. Circ J 2013;77:2226-2231.

3 Hashimoto S, Kawado M, Seko R, Murakami Y, Hayashi M, Kato M, Noda T, Ojima T, Nagai M, Tsuji I: Trends in disability-free life expectancy in Japan, 1995-2004. J Epidemiol 2010;20:308-312.

4 Naruse T, Sakai M, Matsumoto H, Nagata S: Diseases that precede disability among latter-stage elderly individuals in Japan. Biosci Trends 2015;9:270-274.

5 Munakata M: Brachial-ankle pulse wave velocity in the measurement of arterial stiffness: recent evidence and clinical applications. Curr Hypertens Rev 2014;10:49-57.

6 Ikeda A, Iso H, Yamagishi K, Inoue M, Tsugane S: Blood pressure and the risk of stroke, cardiovascular disease, and all-cause mortality among Japanese: the JPHC Study. Am J Hypertens 2009;22:273-280.

7 Yoshimura S, Hasegawa M, Arai C, Abe M, Aizawa Y: Aortic pulse wave velocity and arteriosclerosis (in Japanese). Rinsho Byori 1973;21:79-86.

8 Ouchi Y, Terashita K, Nakamura T, Yamaoki K, Yazaki Y, Toda E, Yamaguchi T, Orimo H: Aortic pulse wave velocity in patients with coronary atherosclerosis - a comparison with coronary angiographic findings (in Japanese). Nihon Ronen Igakkai Zasshi 1991;28:40-45.

9 Takazawa K, Tanaka N, Fujita M, Matsuoka O, Saiki T, Aikawa M, Tamura S, Ibukiyama C: Assessment of vasoactive agents and vascular aging by the second derivative of photoplethysmogram waveform. Hypertension 1998;32:365-370.

10 O’Rourke M: Arterial stiffness, systolic blood pressure, and logical treatment of arterial hypertension. Hypertension 1990;15:339-347.

11 Asmar R, Benetos A, Topouchian J, Laurent P, Pannier B, Brisac AM, Target R, Levy BI: Assessment of arterial distensibility by automatic pulse wave velocity measurement. Validation and clinical application studies. Hypertension 1995;26:485-490.

12 Wilkinson IB, Fuchs SA, Jansen IM, Spratt JC, Murray GD, Cockcroft JR, Webb DJ: Reproducibility of pulse wave velocity and augmentation index measured by pulse wave analysis. J Hypertens 1998;16(pt 2):2079-2084.

13 Sugawara J, Hayashi K, Tanaka H: Arterial path length estimation on brachial-ankle pulse wave velocity: validity of height-based formulas. J Hypertens 2014;32:881-889.

14 Munakata M, Nunokawa T, Tayama J, Yoshinaga K, Toyota T: Brachial-ankle pulse wave velocity as a novel measure of arterial stiffness: present evidences and perspectives. Curr Hypertens Rev 2005;1:223-234.

15 Orlova IA, Nuraliev EY, Yarovaya EB, Ageev FT: Prognostic value of changes in arterial stiffness in men with coronary artery disease. Vasc Health Risk Manag 2010;6:1015-1021.

16 Matsui Y, Eguchi K, Shibasaki S, Ishikawa J, Hoshide S, Shimada K, Kario K: Impact of arterial stiffness reduction on urinary albumin excretion during antihypertensive treatment: the Japan Morning Surge-1 Study. J Hypertens 2010;28:1752-1760.

17 Hong SJ, Choi SC, Ahn CM, Park JH, Kim JS, Lim DS: Telmisartan reduces neointima volume and pulse wave velocity 8 months after zotarolimus-eluting stent implantation in hypertensive type 2 diabetic patients. Heart 2011;97:1425-1432. 
Munakata et al.: Brachial-Ankle Pulse Wave Velocity: Background, Method, and Clinical Evidence

18 Lee JY, Ryu S, Lee SH, Kim BJ, Kim BS, Kang JH, Cheong ES, Kim JY, Park JB, Sung KC: Association between brachial-ankle pulse wave velocity and progression of coronary artery calcium: a prospective cohort study. Cardiovasc Diabetol 2015;14:147.

19 Munakata M, Konno S, Miura Y, Yoshinaga K; J-TOPP Study Group: Prognostic significance of the brachial-ankle pulse wave velocity in patients with essential hypertension: final results of the J-TOPP study. Hypertens Res 2012;35:839-842.

20 Kawai T, Ohishi M, Onishi M, Ito N, Takeya Y, Maekawa Y, Rakugi H: Cut-off value of brachial-ankle pulse wave velocity to predict cardiovascular disease in hypertensive patients: a cohort study. J Atheroscler Thromb 2013;20:391-400.

21 Maeda Y, Inoguchi T, Etoh E, Kodama Y, Sasaki S, Sonoda N, Nawata H, Shimabukuro M, Takayanagi R: Brachialankle pulse wave velocity predicts all-cause mortality and cardiovascular events in patients with diabetes: the Kyushu Prevention Study of Atherosclerosis. Diabetes Care 2014;37:2383-2390.

22 Katakami N, Osonoi T, Takahara M, Saitou M, Matsuoka TA, Yamasaki Y, Shimomura I: Clinical utility of brachial-ankle pulse wave velocity in the prediction of cardiovascular events in diabetic patients. Cardiovasc Diabetol 2014;13:128.

23 Ninomiya T, Kojima I, Doi Y, Fukuhara M, Hirakawa Y, Hata J, Kitazono T, Kiyohara Y: Brachial-ankle pulse wave velocity predicts the development of cardiovascular disease in a general Japanese population: the Hisayama Study. J Hypertens 2013;31:477-483.

24 Takashima N, Turin TC, Matsui K, Rumana N, Nakamura Y, Kadota A, Saito Y, Sugihara H, Morita Y, Ichikawa M, Hirose K, Kawakani K, Hamajima N, Miura K, Ueshima H, Kita Y: The relationship of brachial-ankle pulse wave velocity to future cardiovascular disease events in the general Japanese population: the Takashima Study. J Hum Hypertens 2014;28:323-327.

25 Ishisone T, Koeda Y, Tanaka F, Sato K, Nagano M, Nakamura M: Comparison of utility of arterial stiffness parameters for predicting cardiovascular events in the general population. Int Heart J 2013;54:160-165.

26 Mitchell GF, Hwang SJ, Vasan RS, Larson MG, Pencina MJ, Hamburg NM, Vita JA, Levy D, Benjamin EJ: Arterial stiffness and cardiovascular events: the Framingham Heart Study. Circulation 2010;121:505-511.

27 Kim J, Song TJ, Song D, Lee KJ, Kim EH, Lee HS, Nam CM, Nam HS, Kim YD, Heo JH: Brachial-ankle pulse wave velocity is a strong predictor for mortality in patients with acute stroke. Hypertension 2014;64:240-246.

28 Sheng CS, Li Y, Li LH, Huang QF, Zeng WF, Kang YY, Zhang L, Liu M, Wei FF, Li GL, Song J, Wang S, Wang JG: Brachial-ankle pulse wave velocity as a predictor of mortality in elderly Chinese. Hypertension 2014;64: 1124-1230.

29 Sugawara J, Tanaka H: Brachial-ankle pulse wave velocity: myths, misconceptions, and realities. Pulse (Basel) 2015;3:106-113.

30 Sugamata W, Nakamura T, Uematsu M, Kitta Y, Fujioka D, Saito Y, Kawabata K, Obata JE, Watanabe Y, Watanabe K, Kugiyama K: Combined assessment of flow-mediated dilation of the brachial artery and brachial-ankle pulse wave velocity improves the prediction of future coronary events in patients with chronic coronary artery disease. J Cardiol 2014;64:179-184.

31 Kitahara T, Ono K, Tsuchida A, Kawai H, Shinohara M, Ishii Y, Koyanagi H, Noguchi T, Matsumoto T, Sekihara $\mathrm{T}$, et al: Impact of brachial-ankle pulse wave velocity and ankle-brachial blood pressure index on mortality in hemodialysis patients. Am J Kidney Dis 2005;46:688-696.

32 Tomiyama H, Koji Y, Yambe M, Shiina K, Motobe K, Yamada J, Shido N, Tanaka N, Chikamori T, Yamashina A: Brachial-ankle pulse wave velocity is a simple and independent predictor of prognosis in patients with acute coronary syndrome. Circ J 2005;69:815-822.

33 Morimoto S, Yurugi T, Aota Y, Sakuma T, Jo F, Nishikawa M, Iwasaka T, Maki K: Prognostic significance of anklebrachial index, brachial-ankle pulse wave velocity, flow-mediated dilation, and nitroglycerin-mediated dilation in end-stage renal disease. Am J Nephrol 2009;30:55-63.

34 Meguro T, Nagatomo Y, Nagae A, Seki C, Kondou N, Shibata M, Oda Y: Elevated arterial stiffness evaluated by brachial-ankle pulse wave velocity is deleterious for the prognosis of patients with heart failure. Circ J 2009; 73:673-680.

35 Miyano I, Nishinaga M, Takata J, Shimizu Y, Okumiya K, Matsubayashi K, Ozawa T, Sugiura T, Yasuda N, Doi Y: Association between brachial-ankle pulse wave velocity and 3-year mortality in community-dwelling older adults. Hypertens Res 2010;33:678-682.

36 Nakamura M, Yamashita T, Yajima J, Oikawa Y, Sagara K, Koike A, Kirigaya H, Nagashima K, Sawada H, Aizawa T: Brachial-ankle pulse wave velocity as a risk stratification index for the short-term prognosis of type 2 diabetic patients with coronary artery disease. Hypertens Res 2010;33:1018-1024.

37 Turin TC, Kita Y, Rumana N, Takashima N, Kadota A, Matsui K, Sugihara H, Morita Y, Nakamura Y, Miura K, et al: Brachial-ankle pulse wave velocity predicts all-cause mortality in the general population: findings from the Takashima study, Japan. Hypertens Res 2010;33:922-925.

38 Kato A, Takita T, Furuhashi M, Kumagai H, Hishida A: A small reduction in the ankle-brachial index is associated with increased mortality in patients on chronic hemodialysis. Nephron Clin Pract 2010;114:c29-c37.

39 Tanaka M, Ishii H, Aoyama T, Takahashi H, Toriyama T, Kasuga H, Takeshita K, Yoshikawa D, Amano T, Murohara T: Ankle brachial pressure index but not brachial-ankle pulse wave velocity is a strong predictor of systemic atherosclerotic morbidity and mortality in patients on maintenance hemodialysis. Atherosclerosis 2011;219:643-647. 
40 Yoshida M, Mita T, Yamamoto R, Shimizu T, Ikeda F, Ohmura C, Kanazawa A, Hirose T, Kawamori R, Watada $\mathrm{H}$ : Combination of the Framingham risk score and carotid intima-media thickness improves the prediction of cardiovascular events in patients with type 2 diabetes. Diabetes Care 2012;35:178-180.

41 Inoue T, Ogawa T, Ishida H, Ando Y, Nitta K: Aortic arch calcification evaluated on chest X-ray is a strong independent predictor of cardiovascular events in chronic hemodialysis patients. Heart Vessels 2012;27:135-142.

42 Chang LH, Lin HD, Kwok CF, Won JG, Chen HS, Chu CH, Hwu CM, Kuo CS, Jap TS, Shih KC, Lin LY: The combination of the ankle brachial index and brachial ankle pulse wave velocity exhibits a superior association with outcomes in diabetic patients. Intern Med 2014;53:2425-2431.

43 Yoon HE, Shin DI, Kim SJ, Koh ES, Hwang HS, Chung S, Shin SJ: Brachial-ankle pulse wave velocity predicts decline in renal function and cardiovascular events in early stages of chronic kidney disease. Int J Med Sci 2013;10:1430-1436. 